\title{
Gradience and linguistic change
}

Link to publication record in Manchester Research Explorer

\section{Citation for published version (APA):}

Denison, D. (2001). Gradience and linguistic change. In L. J. Brinton (Ed.), Historical linguistics 1999: Selected papers from the 14th International Conference on English Historical Linguistics (Current Issues in Linguistic Theory) (pp. 119-144). (Current Issues in Linguistic Theory; Vol. 215). John Benjamins Publishing Company.

\section{Published in:}

Historical linguistics 1999

\section{Citing this paper}

Please note that where the full-text provided on Manchester Research Explorer is the Author Accepted Manuscript or Proof version this may differ from the final Published version. If citing, it is advised that you check and use the publisher's definitive version.

\section{General rights}

Copyright and moral rights for the publications made accessible in the Research Explorer are retained by the authors and/or other copyright owners and it is a condition of accessing publications that users recognise and abide by the legal requirements associated with these rights.

\section{Takedown policy}

If you believe that this document breaches copyright please refer to the University of Manchester's Takedown Procedures [http://man.ac.uk/04Y6Bo] or contact uml.scholarlycommunications@manchester.ac.uk providing relevant details, so we can investigate your claim.

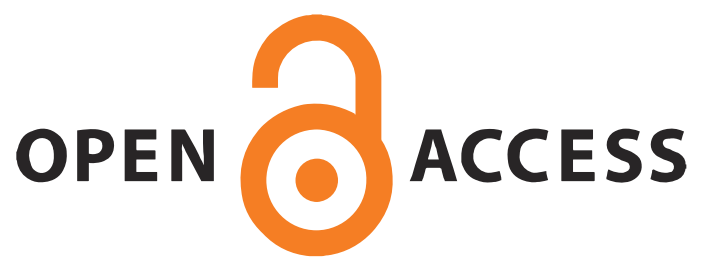


Denison, David. 2001. Gradience and linguistic change. In Laurel J. Brinton (ed.), Historical linguistics 1999: Selected papers from the 14th International Conference on Historical Linguistics, Vancouver, 9-13 August 1999 (Current Issues in Linguistic Theory 215), 119-44. Amsterdam and Philadelphia PA: John Benjamins. http://benjamins.com/\#catalog/books/cilt.215/main

\title{
Gradience and linguistic change
}

\author{
David Denison \\ University of Manchester
}

\section{Introduction $^{1}$}

Syntactic categories

In some traditional grammatical approaches such as that embodied in the National Literacy Strategy for primary schools in England, adjectives are "words which qualify nouns" (anon. 1998:34). (In fact even the with-phrase in the girl with long hair is called an Adjective Phrase in the original version of the NLS Glossary, 1998:85. $)^{2}$ It is clear too that a modifying noun is regarded as an adjective. Consider (1), noticed on the side of some Vancouver ambulances:

(1) Advanced Life

Support Unit

Although (1) seems straight out of Douglas Adams or Steven Spielberg, it isn't the bracketing that is relevant here but the categories. Anyone relying on the original NLS documentation, which has a poor definition of Adjective and little conception of structure, would have to find three adjectives in (1). Now Rodney Huddleston (1984:93-5, 325-8), for example, shows that this is a wrong-headed analysis which confuses form class, to be defined by a basket of properties, with function, and ever since I first read his book many years ago I have subscribed to that careful structuralist view: a modifying noun remains a noun. I will return to the distinction between adjectives and nouns. This paper concerns the boundaries between word classes and the consequences for syntactic analysis. I will claim that treatments of word classes, in linguistics as much as in the traditional view, are often inadequate, in particular by showing that certain individual words and constructions defy simple categorisation and analysis. The focus throughout is on recent change in English, and synchronic analysis is harnessed to diachronic explanation. 


\section{David Denison}

\section{Some recent approaches}

\section{Chomskyan grammar}

By way of introduction, let me now risk caricaturing some respectable and modern linguistics. Much generative grammar assumes that a given sentence has a unique analysis for a given speaker (possibly involving a derivational history, of course), with each of its component words having a unique category: an item either is a noun or it isn't, for instance. ${ }^{3}$ An important goal of theorising is to make the overall grammar as economical as possible, usually expressed as a necessity for explaining the miracle of language acquisition, less often to allow for on-line processing. Rather than being directed to the limitations of childhood language learners, this economy drive is perhaps at least as much to do with perceptions of elegance among (mathematically inclined) linguists - a matter of aesthetics.

One development within this tradition, often favoured by those interested in diachrony, allows competing grammars à la Kroch and Pintzuk, recent examples being Henry (1997) and Lightfoot (1999). Variation is handled by allowing that different grammars may co-exist within a society and even within an individual normally two grammars; most choices remain binary. (Henry allows three in her study of imperatives, but only one per individual.) But every variation needs a set of grammars, so that except where different cases of variation can be shown to be related to a single parameter setting, this rapidly becomes an unrealistic model of variation.

\section{Optimality Theory}

An alternative theoretical development is along the route of Optimality Theory, where one aspect of economy is jettisoned, in that the grammars for all human languages and varieties contain the same huge number of rules and differ only in the ordering and salience of the rules, and where one aspect of Procrustean rigour or rigidity is jettisoned by allowing those rules to be violable rather than absolute. However, the underlying representation of any given sentence is typically couched in one of the standard formalisms (for example, a Chomskyan generative syntax or Lexical-Functional Grammar), with unambiguous structural relations and category assignment. All the generative approaches so far mentioned are synchronic approaches at heart, and all concentrate on patterns.

\section{Economy}

If overall economy and maximal efficiency of analysis remain top priorities, certain things follow. The speaker has a grammar. All of his or her possible sentences are in principle describable, are predictable, from a single, 
self-consistent, elegant grammar conforming to UG. Any messiness is an essentially uninteresting matter, certainly not part of I-language.

Binarity of parameter settings, of choices between clear Aristotelian categories, and so on, is an understandable move, and a reasonable heuristic. Systems embodying binarity and economy are apparently simpler to describe, and their mathematical properties are easier to state. Questions about the power of the grammar and hence of its falsifiability can be asked and answered. Such approaches started very much as top-down analyses, even if the drive over the last twenty or so years has been increasingly towards modularity by interaction of relatively simple explanatory principles.

However, there is another view of economy which suggests that an individual speaker need not have a wholly consistent grammar. It may be - in my view, it may well be - that speakers are capable of routinely using fragments of language which are mutually inconsistent. Speakers may in part organise language at a much more local level. The patterning involved may be less neat but not necessarily more complex. This would be a bottom-up model. The view that an individual's grammar may not be homogeneous is subscribed to by, among others, Harris \& Campbell (1995). Croft (2000:231) quotes a nice line by Bolinger: "I want to suggest that language is a structure, but in some ways a jerry-built structure" (1976:1).

The idea that the best analysis of a construction comes from a model in which only one derivation is possible always struck me as psychologically implausible. In a paper I wrote some fifteen years ago on Old English word order I suggested the following:

Rather than a given sentence being the output of some maximally simple, elegant, and maybe unique rule, I regard a sentence as the more likely, the more (potentially conflicting) requirements it satisfies simultaneously, thus the more patterns it matches. (Denison 1986:293)

That rather programmatic statement is somewhat in the spirit of the later Optimality Theory, in which grammaticality derives from the resolution of a large number of possibly conflicting attempts to satisfy particular conditions. It is equally consonant with a theory embracing gradience, regarded as the simultaneous resemblance to different and incompatible prototypes.

\section{Grammaticalisation}

Yet another approach which commands widespread recognition is Grammaticalisation Theory. Here we have a rather different point of view: essentially diachronic, essentially gradualist, and in its synchronic consequences involving co-existence of more and less grammaticalised variants in the same variety. Grammaticalisation typically concerns itself with individual lexical 


\section{David Denison}

items, at least at the input stage, and with transitions from major lexical word classes to more functional elements (though there are exceptions to the latter, as in Werner Abraham's and Paolo Ramat's contributions to 14ICHL). In this paper I will try to stick to examples of gradience which would not normally be regarded as either grammaticalisation or degrammaticalisation, as I am interested in exploring the question of gradience as a more widespread phenomenon in language.

\section{Notional grammar}

John Anderson's Notional Grammar (1997 and earlier papers) appears to embody gradience, in that a scale of categories runs from complete N (Referentiality, nominality of proper name) to complete $\mathrm{P}$ (Predicability, finite verbality), with as many intermediate points between $\mathrm{N}$ and $\mathrm{P}$ as are thought necessary. But any given category - for instance, the gerund, the adjective, whatever — is assigned a fixed point on this scale, which can be represented in effect as a particular numeric proportion of $\mathrm{N}$ to $\mathrm{P}$. I want here to explore gradience between categories which are not necessarily adjacent on Anderson's scale, and also to consider the idea that a given item doesn't always have a fixed place on that single scale.

\section{A project on gradience}

\section{Context of this paper}

There is no room here for a properly extensive discussion of linguistic theory. What I have attempted above is the merest sketch of some salient characteristics of different approaches, in order to provide a context for what follows: a preliminary survey of some gradient phenomena in grammar. This is a return to a topic which I looked at unsystematically in the 1980s and which I hope to develop with Bas Aarts of University College London as a major research project. It takes two ideas as its starting-points:

- that language routinely exhibits gradient boundaries in the synchronic state

- that linguistic change may proceed by means of, perhaps even because of, gradient stages

The first point is noted by many writers, for example — with increasing degrees of emphasis - Huddleston (1984:72), Quirk et al. (1985:90), and Langacker (1987:18).

As for the second, gradience in change does not necessarily mean gradualness chronologically. Lightfoot (1999) and others have argued that apparent gradualness of change in the historical record may be compatible with sudden grammatical change at the level of the individual speaker. At present I am 
working on the assumption that gradience in a certain historical change means that the change occurs by means of a number of small steps, but I do not assume that progress through a series of steps must be prolonged in time, so this is potentially the exact opposite of Lightfoot's approach.

In the proceedings of a conference like ICHL with no $\mathrm{E}$ in the acronym, I must ask forgiveness for appearing to assume, like the worst kind of 1960s synchronic transformational grammar, that the business of linguistics can be conducted solely on the basis of English data. I don't for one moment think that, but my examples here are all from the recent history of English.

\section{Taxonomy of gradience}

A taxonomy which Bas Aarts has been developing now simply distinguishes gradience within a form class and gradience between form classes. The first is almost uncontroversial. Thus it is a truth more or less universally acknowledged within linguistics that the form class 'Adjective' is defined by a cluster of distributional properties, and that adjectives which satisfy all of them - wide, happy, etc. - are more prototypical members of the class in English than items like mere, potential, dead, ill which satisfy some but not all of the properties. Nevertheless those marginal members of the class are still universally recognised as being adjectives: no other form class seems appropriate. If it is conceded that there are degrees of closeness to the prototype, then we have gradience within a single form class, what Aarts calls 'subsective gradience'.

Gradience between two form classes he calls 'intersective gradience', but Aarts adopts the working assumption that most claimed examples of intersective gradience between category A and category B in synchronic linguistics are unnecessary complications of the grammar which, by more careful or delicate analysis, can be decided as either A or B but not both. Diachronically, however, the possibility of intersective gradience between form classes seems to me still worth considering, and it often co-occurs with intersective gradience between constructions. Here a given sentence type manifests behaviour which suggests two different structures at the same time.

I think it is fair to say that subsective gradience is quite widely acknowledged (not under that name, of course), in the sense that most scholars would subscribe to it, even though it is rarely built into theories. Intersective gradience between categories has been looked at by a few scholars, and between constructions is not generally acknowledged at all. Where gradience has been dealt with in the literature it has mostly involved placing different items along a gradient. I move on now to discussion of possible gradience on the basis of real data. Sometimes I illustrate gradience by assigning different positions on a gradient to different occurrences of the same word or syntactic pattern. 


\section{David Denison}

\section{Subsective gradience}

Given that subsective gradience is relatively familiar, I will add just two further examples.

\section{Modal membership}

Some modals are less central than others. This is much-visited territory. So, for instance, CAN and WILL were the last modals to become wholly grammaticalised in the early Modern English (eModE) period — see here Warner's (1990) account while in Present-day English (PDE), OUGHT is more marginal than the prototypical modals. Recently MAY has been showing signs of obsolescence, and its form may is losing paradigm modal properties like present tense distribution and clitic negation (Denison 1998:177-8, 197). Within the category Modal, then, there has always been subsective gradience.

\section{less ( $c f$. more)}

See Quirk et al. (1985:262-4) for some discussion of quantifiers like more and less. Here, I will suggest, we find a kind of gradience. If this is gradience wholly within a category, presumably we must call it subsective, but if so, it is subsective gradience of a problematic kind. First, it is a moot point precisely which category to use for less: Quantifier, Post-determiner, or Determiner, in increasing order of generality ${ }^{4}$ Second, there is no obvious prototypical core unless we take an item like the as the prototypical Determiner, in which case Post-determiner and Quantifier would already have to be consigned to the periphery - so that a definition of subsective gradience which depends on distance from a prototype would be difficult to apply.

Now consider the following material, adapted from my recent survey of late ModE syntax (Denison 1998:124):

(2) noncount nouns count nouns

more work $\quad(\mathrm{mo}) \rightarrow$ more students

less work fewer $\rightarrow$ less students

The quantifiers show some changes of usage over time. Already with the loss of $m o$ in the eModE period, more had come to be used both with noncount and count nouns. Less has a strong tendency to behave similarly, and in fact did so between Old English and the sixteenth century. Usages like less raindrops then became stigmatised, and in standard English a distinction has until recently been made between less and fewer: less work, but fewer students. Now probably most younger speakers would say less students. OED already has a few nineteenth-century citations of less Ns. Within the last generation or so, the usage has become increasingly frequent, and the current revival seems inexorable, given the strong pressure of analogy. ${ }^{5}$ So what about the following example? 
Gradience and linguistic change 7

(3) Capt. Goldsmith, a young Surrey officer, came with me for the first couple of hours, with a party of 19 mounted police - for honour you understand, not for safety. I could have done with less but in spite of them all the ride over the desert green with aromatic plants was delicious. (1918 Bell, Letters II.451 (28 Mar.))

When I first discussed example (3) (Denison 1998), I wrote that the modern reader is likely to interpret less as "less policemen", whereas the highly educated Gertrude Bell more probably understood something like "less honour" or "a smaller party". But perhaps not, since less is not directly followed by a plural noun. Such environments have long been somewhat more acceptable for less in the sense "fewer", e.g.

(4) (no) less than twenty students

(5) groups of twenty students or less

This looks, therefore, like a case of (re-)introduction of an innovation through the least salient point. Less in very conservative varieties is a quantifier like much which collocates with noncount head nouns only; in more advanced varieties it is like more and collocates with both count and noncount head nouns. (That is a recurrent distinction within the Determiner category; see Quirk et al. 1985:377-85, Tables $6.45,6.48,6.49,6.53$.) But moderately conservative usage (e.g. my own) — which allows (4) and maybe (5) but not less students - shows fairly stable subsective gradience in the usage of less, part-way between the much type and the more type.

\section{Intersective gradience between categories}

Gerund

The classic example of a mixed category is the gerund, which blurs the distinction between $\mathrm{N}$ and $\mathrm{V}$, and used to do so even more than is now normal. Despite distributional changes in the last two centuries, there are still examples where nominal behaviour (modification by a determiner) coexists with verbal behaviour (complementation by objects, etc.):

(6) The days had been very full: the psychiatrist, the obstacle courses, the throwing herself from the hold of a slowly chugging plane (1998 Sebastian Faulks, Charlotte Gray [Vintage, 1999] x.111)

The gerund is much-analysed topic, too big to go into here; for some historical discussion see Denison (1998:268-72) and references given there. I now turn to some further instances of intersective gradience. 


\section{David Denison}

$N \sim A$

The distributions of A(djective) and N(oun) are different. Within the NP — the choice between a DP and NP analysis is not germane in this rather "surfacey" account - the usual descriptive statement is that the possible items are as follows: (7) $\mathrm{D} \quad \mathrm{A}^{1-\mathrm{n}} \mathrm{N}^{1-\mathrm{n}} \mathrm{N}_{\text {head }}$ Postmodifiers ${ }^{1-\mathrm{n}}$

That is to say, there is a single $\mathrm{D}$ (eterminer) slot (ignoring for now pre- and post-determiners), an iterative slot for modifying adjectives, an iterative slot for modifying nouns, and then the head noun; after that come any postmodifying elements. Crucially, all premodifying adjectives precede all premodifying nouns:

(8) a. National Literacy Strategy

b. *Literacy National Strategy

$N \rightarrow A$

Are there words which have moved from noun to adjective over time? I should point out that the "bible" of English word formation doesn't recognise such a process: "No transposed substantive can be called an adjective unless it has received a categorial marker" (Marchand 1969:361), that is, a derivational suffix or other explicit change of form. Other writers do, however, at least in a limited way. Huddleston writes (1984:328):

There will then be very little occasion to postulate conversion from noun to adjective. Where we can add degree adverbs as dependents, as - for some speakers at least - in a very fun party, an extremely Oxbridge accent, we will certainly regard the degree of adjectivalisation such as to justify a conversion analysis, but there are not many examples of this kind.

For noun $\rightarrow$ adjective conversion - as opposed to the "partial conversion" (in fact, non-conversion) shown in the wealthy and similar phrases - Quirk et al. have relatively few examples, most of them words for materials like brick, stone (1985:1562), thus objective, non-evaluative modifiers. I show now that there are others of more subjective, evaluative semantics and thus potentially "better" adjectives.

\section{Powerhouse}

(9) Raves coming thick and fast for George Auld's new powerhouse band now at the Arcadia Ballroom, N.Y. (1942 [OED])

(10) The powerhouse new bestseller from ELIZABETH GEORGE (1996 Bantam Press advertisement, The Guardian p. 1 (3 Feb.))

Example (10) shows that the former noun modifier of (9) has now (at least once) been used as an adjective, but the word powerhouse as modifier is too rare for me to detect gradience in the transition. ${ }^{6}$ 
Gradience and linguistic change 9

\section{Fun}

This is a more common word, already noted in this connection by previous scholars, and a range of examples can be found: ${ }^{7}$

(11) Painting is more fun and less soul-work than writing. (1927 [OED])

(12) It was such fun.

Fun is clearly a noun in (11) and (12). Like all nouns, fun can be used as a noun modifier:

(13) I was remembering Marianne and the fun times we have had. (1968 [OED]) This kind of usage neutralises the $\mathrm{N} \sim$ A distinction.

In (14) fun looks somewhat more adjectival:

(14) She's so completely lovely and fun and joyful. (W1B-003 \#73:1 [ICE-GB]) Here it occurs in a coordinated sequence of what are otherwise clear adjectives (but without becoming itself an unequivocal adjective, cf. It's lovely but a mess).

In (15)-(18), however, fun shows distinctively adjectival behaviour in its syntax:

(15) We have the Osborns, the Beals, the Hartungs, the Falmers, and us. Now let's think of someone fun. (1971 [OED])

(16) ... perhaps send for that book you never bought earlier and have a really fun time with the wealth of designs from Iris Bishop or Wendy Phillips or whoever you like best. (CA2 553 [BNC])

(17) It may not be as fun to watch it up close (A17-113 [Frown])

(18) It was so fun. (1999 att. DD)

In (15) it postmodifies an indefinite pronoun; in (16)-(18) it is premodified by an intensifier or conjunction which typically co-occurs with adjectives rather than nouns. The contrasting examples (12) and (18) represent normal usage in different generations of my family. Leech \& Li (1995:187) also mention "the adjectival use of fun both predicatively and attributively (as in The event was fun and It was a fun event)", which takes to "its fullest form" what they identify as "the tendency for Noun Phrase complements to gravitate towards adjectival use".

A superlative - sign of full morphological adjectivehood - appears in the following journalistic parody:

(19) Valspeak is..the funnest, most totally radical language, I guess, like in the whole mega gnarly city of Los Angeles. (1982 [OED Online])

Key

This word shows similar behaviour. It can of course be a noun - indeed normally is so. There is a longstanding use as noun modifier, as in:

(20) Occupants of key offices such as the Presidency or the Attorney-Generalship. (1926 [OED])

Interestingly, $O E D$ labels this usage as follows (s.v. key n. $\left.{ }^{1} 17 . b\right)$ : 
Passing into adj. in the sense of 'dominant', 'controlling', 'chief', 'essential'; esp. designating some person or thing that is of crucial importance to others.

Here is another example, where the near-synonymy of key with the adjective crucial is explicit:

(21) The key verse in this first section is verse 4; it is a crucial one. (1959LLOY.H9 [ARCHER])

However, on the Huddleston analysis the modifier key in (20)-(21) would still be a noun, since until quite recently key did not show criterial properties of adjectives other than occurrence in premodifier position, which is available for nouns too.

In some cases there is a subtle further development in usage:

(22) Another source said that the interview with Jaafar's family did not provide any helpful leads and indicated that Jaafar did not play any key role in the case. (1989LAT1.N0 [ARCHER])

This and other examples show that key is losing the sense of uniqueness, which may eventually lead to semantic gradability. ${ }^{8}$ Word order too is suggestive:

(23) a. But the key foreign and defense portfolios remained unchanged. (1982CHI2.N0 [ARCHER])

b. two key Southern states (S2B-006 \#9:1:B [ICE-GB])

(24) More emotional weight is carried in the key domestic scenes in which ... (C01 103 [FLOB])

Use before adjectives may not be wholly convincing evidence of adjectivehood, despite (7) and (8), since foreign portfolio, defense portfolio and Southern states are institutionalised phrases. What would be happening in (23) would then be that the ordering of subjective/evaluative modifiers before modifiers expressing provenance and so on (a matter of semantics, pragmatics or discourse) is overriding the ordering of categories, of A before $\mathrm{N}$ (a matter of syntax). But even if so, this is gradience, and (24) is better evidence of a category change, since domestic scenes is not obviously a set phrase.

A further development is illustrated in (25):

(25) a. "Claudia brings an unforgettable quality of joy to all her work that is key to Revlon's view of beauty". (FBM 759 [BNC])

b. The agreement of a mutually acceptable reserve price is key. (HJ5 1349 $[\mathrm{BNC}])$

c. Noting that such incidents are not marginal but key to Edgeworth's plots, ... (1992 M. Butler, "Introduction" p.41, Maria Edgeworth, Castle Rackrent and Ennui, Penguin)

Now key is being used without a determiner, very much like fun, and in (25)c is coordinated with an adjective.

Finally, we see a significant further step:

(26) There are a number of reasons why people lose their hair, stress is a very key factor. (HVE 174 [BNC]) 
(27) we are fast approaching a very key point er in that process erm [...] and the key point, which really is arises out of what we're discussing tonight, the key point is what regulatory framework should the P I A place on intermediaries and on er life assurance companies, pension funds, financial advisors generally (JSG 337 [BNC])

Now key is being used with very: this must be an adjective. (Notice too the anacoluthic clause which really is in (27), which also implies gradability.) A syntactic superlative appears in:

(28) Meirion Rowlands, one of the Ashleys' most key appointments of this time, was well known as the local prizewinning sheep shearer; he met Bernard over a pint in the pub. (GU9 7 [BNC])

And yet the same speakers who might use (28) would still (I believe) accept as another instance of the same word:

(29) Fear is the key.

(30) Fear and ambition are the respective keys to their characters.

Reviewing the examples of key in this section, we appear to have nouns (20), (29), (30), etc. — adjectives - (26)-(28), etc. — and several intermediate types all current in the language. My point is that there is no simple switch from $\mathrm{N}$ to $\mathrm{A}$, rather a graded series of transitions. If that is so, then we have demonstrated synchronic gradience.

\section{Designer}

A similar process is happening with designer. For brevity I cite some NPs to illustrate its use before an institutionalised $\mathrm{A}+\mathrm{N}(\mathrm{N}-$ bar) phrase:

(31) The designer Italian menu (ECU 2974); so it's finally happened -- designer industrial action (ANY 2084); Designer interior decoration (BMD 1695);

from under the designer fitted units (CB8 3479 [BNC])

On West $10^{\text {th }}$ Avenue in Vancouver you can see a shop-front which says:

(32) Designer Direct Sofas.

In (31) and (32) the modifier designer, originally a noun, is occurring before adjective modifiers, albeit adjectives which form set phrases with their head noun. This could be the beginning of a gradient for designer which might take it towards being a true adjective itself.

Many of my students say they would find the following quite normal:

(33) Those sunglasses are very designer.

(34) Those sunglasses look designer.

For them it has taken another step towards adjective-hood. 


\section{David Denison}

$A \rightarrow N$

Going the other way is not (obviously) a matter of gradience. "There is no very productive pattern of adjective $\rightarrow$ noun conversion" (Quirk et al. 1985:1560). "Miscellaneous examples" given by the Quirk team include bitter, daily, final, where derivation involves ellipsis of a noun head from well-established A+N=NP phrases. Another straightforward example can be constructed from citations for the word elastic in $O E D$ :

(35) Elastic Bitumen..is of a brown color, has no lustre, and is very elastic. (1794)

(36) Cavallo in Phil. Trans. LXXI. 519 Common vitriolic ether..could not affect elastic gum. (1781)

(37) With the elastics supplied by the ladies, for a halter..the young dog passed from the shores of time. (1847)

(38) Adèle had been enquiring for a piece of elastic for her hat. (1863)

In (35)-(36) elastic is an adjective; in (37)-(38) it is being used as a noun. I am content to regard this as an abrupt change. Note that once again Marchand (1969:361) doesn't recognise any synchronic relationship here:

Some of these elliptic expressions [sc. hopeful < hopeful candidate] have gained complete independence from their original full syntagma basis, as is the case with musical. The word is no longer thought of as a shortening of musical comedy, but has become a sb in its own right. The final result is an unmotivated new moneme [...] Unmotivated signs, however, do not belong in word-formation.

Intersective gradience between $N$ and $A$ ?

Among the basket of properties normally used for defining Noun is the possibility of plural marking: this is to be contrasted with Adjective, which lacks it. Both classes share the distributional property of occurring as premodifiers of nouns in that position the distinction between them is partially neutralised - but it is interesting that a noun premodifying another noun is typically not plural:

(39) a. trouser-press, child support

b. *trousers-press, *children support

Quirk et al. note that plural marking is absent here even for what they call "summation plurals" like trousers which otherwise do not occur without a plural inflection (1985:301).

Here, then, an adjective-like position is associated with one aspect of adjective-like morphology. Furthermore a noun in that position won't have a determiner of its own, and even when used elsewhere and acting as a head may be a noncount noun (fun, for example) and so potentially without determiner even then. Potential for use with a determiner helps to distinguish Noun from Adjective, so the $\mathrm{N} \sim \mathrm{A}$ distinction is further blurred. Again, Leech \& $\mathrm{Li}$ 
(1995:186) mention in a different context — complement NPs — "a tendency to omit the article initiating an NP, a characteristic which ... gives the NP a more adjectival quality". The conclusion I am driven to is that the traditional usage reflected in the National Literacy Strategy which I mentioned and mocked at the start — "noun used as adjective" is a common version - may not be entirely wrong-headed: we can see from the kinds of fact discussed here why it has seemed reasonable to so many people.

What is interesting about the trading relationship between Noun and Adjective is that there seems to be some directionality. So far I haven't come across examples of category shift which move in opposite directions along exactly the same gradient. There are different routes from one category to the other.

\section{$A \sim P:$ transitive adjectives}

A notorious case of uncertain categorial status is the 'transitive adjectives' like, worth and near. Consider PDE examples complemented by an NP:

(40) a. like a man

b worth a lot of money

c. near the river

The structures in (40) bear considerable resemblance both to AP and to PP, so the category of the head is correspondingly uncertain: A(djective) or $\mathrm{P}$ (reposition)? This might be one case of what Ross $(1972,1973)$ calls a 'squish'. Maling (1983) categorises the first two items as prepositions, the third as an adjective, and Anderson (1997:74-82) places them along a gradient between adjective and preposition in the order near, like, worth, whereas Quirk et al. treat all of them as prepositions but with greatest hesitation over like (1985:661-3, 1064 n.[c]). I will not repeat the distributional evidence in detail, but it is clear that these words pose some problem for the categorisation of PDE lexemes.

When considered historically, such words generally become less problematic over time, revealing a sharpening of categories. We might add (un)becoming, (un)worthy, next, which fell nearer to the $\mathrm{P} \sim \mathrm{A}$ border earlier in the late ModE period:

(41) a. and any such feeling on her part was mean, ignoble, and unbecoming the spirit with which she wished to think that she was endowed. (1860-1

Trollope, Framley xxxv.343)

b. to make the subject well worthy the attention of all who have occasion to treat diabetes mellitus. (1868PINK.M7 [ARCHER])

c. The end of the piece which was next the now detached pipe, is called the nose. $(1880[O E D])$

It is noticeable that (un)becoming, (un)worthy, and next have virtually lost all prepositional character and become wholly adjectival. ${ }^{9}$ There were, arguably, 


\section{David Denison}

many more transitive adjectives in Old English, but all have lost their NP-governing character.

Conversely, like has lost some adjectival properties:

(42) a. A nation means a like body of men, because of that likeness capable of acting together. (1872 [OED])

b. It was very like and very laughable, but hardly caricatured. (1854 $[O E D])$

c. The two or three places I am like to have business relations with. (1886 $[O E D])$

The patterns of (42) are pretty much obsolete. The main uses now of like are as preposition (or 'quasi-prepositional adverb', as $O E D$ would have it) and increasingly as conjunction/complementiser, a pairing which in some analyses is a single category anyway (for example, Emonds 1976, Huddleston \& Pullum in prep.):

(43) a. He entered like a whirlwind. (cf. He died before his time.) [+ NP]

b. He acted like there was no tomorrow. (cf. He left before it finished.) [+ clause]

As for worth, use without a dependent NP or clause - and therefore as pure adjective - has been obsolete for centuries: OED's last citation is dated a1450 (s.v., 4.a) or possibly 1535 (s.v., 6).

All of the words just discussed have thus been moving away from peripheral joint membership of the two categories $\mathrm{P}$ and $\mathrm{A}$ and towards membership of a single category (even if they have not all yet attained prototypical membership). The particular direction each one has taken gives some support to Maling's analysis of their PDE distributions. Only near obstinately keeps a foot in both adjectival and prepositional camps. ${ }^{10}$ So we may be able to conclude that (intersective) 'squish' or something like it is necessary in linguistic categorisation, but also that items can lose some of their squishiness over time.

I don't know if there is a tendency for intersective gradience to be unstable, though I suspect so. It would fit plausibly with Warner's suggestion of a tendency for category distinctions which are 'basic' in the Roschian sense to be sharpened over time: ${ }^{11}$ "[O]nce an opposition becomes basic its internal coherency and external distinctiveness should tend to increase, if opportunity offers." (1990:550). But then we face the problem that confronts every proponent of a historical account in which some structure or other is said to be disfavoured: if it is so low-valued: how come it ever arose in the first place? 


\section{Intersective gradience between constructions}

Given that this type of gradience is perhaps least familiar, I discuss a number of possible examples.

\section{Partitives, kind of}

It is possible to analyse an NP (again, I am not taking it as a DP) like a majority of students in two ways:

(44) a. head noun majority, premodified by determiner $a$ and postmodified by the prepositional phrase of students (cf. a steak in breadcrumbs)

b. head noun students, premodified by complex determiner a majority of (cf. a few students)

For conflicting views see Huddleston (1984:236-9), Quirk et al. (1985:264, 764-5). Analysis (44)a corresponds to the syntactic origin of the pattern, while there is some semantic support for (44)b, in that a majority of students is notionally more likely to be a partitive of students than a kind of majority. The most obvious test of structure is verbal concord: with singular majority or with plural students? For quite a number of phrases, the historical development has been a classic process of replacement: first analysis a alone, then $a$ and $b$ in variation, and finally $b$ alone. The older structure is shown in:

(45) The progress of phonetics has been so great ... that the great bulk of the observations already made on living languages is next to useless. (1873-4

Sweet, "On Danish Pronunciation", TPhS 94)

The newer structure appears in:

(46) a crowd of people were arguing with and even shoving the Guards, ... (1906 Nesbit, Amulet xi.206)

Both variants exist today in:

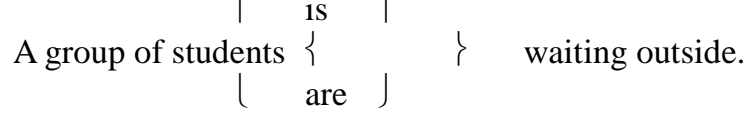

With the majority example already discussed, the singular variant is now somewhat pedantic and is probably obsolescent. And with a lot of the singular construction has disappeared entirely (and of course was never found with the plural variant lots of). Informal English even permits concord between a plural (notional) head noun and a central determiner which, historically speaking, should be the modifier of a singular noun and thus singular in form:

(48) a. These sort of ideas (1788 Betsy Sheridan, Journal 42 p. 131)

b. those sort of jokes (1949 Streatfeild, Painted garden xxiii.256)

Such examples — Quirk et al. have a similar one with kind of (1985:764) — give additional support to analysis (44)b over and above verbal concord, with sort of functioning syntactically as a kind of postdeterminer. 
Nonpartitives like a tiny stifling box of a place (1917 Bell, Letters II.405) and a/one hell of a party (cf. also the common spelling helluva) may show a rather similar shift from head to part of premodifier; see here Aarts (1998), OED s.v. of prep. 24.

What is the nature of the diachronic shift from one analysis to another, and of the synchronic variation between analyses? Timberlake (1977), for instance, assumes that a diachronic process of reanalysis requires some contexts which are structurally ambiguous. Reanalysis in such contexts is followed by a gradual process of actualisation in which the reanalysed variant extends its distribution. It is implicit in his account that there are only two possible analyses - what we might call 'before' and 'after' — and that any one speaker at any one time assigns only one of these analyses to a given string. Some generative accounts of phenomena like the prepositional passive have built reanalysis into synchronic derivations, so that a speaker could have different structural analyses at different stages of a sentence's derivation; for some references and discussion see Denison (1993:151-2), Haspelmath (1998). Even in a synchronic reanalysis account, though, there is in effect a 'before' and an 'after' (not to be interpreted temporally, of course) and nothing in between. Prima facie, however, I believe that we can make a case for intersective gradience diachronically and probably synchronically too. The argument runs as follows.

Within the partitive construction type in Present-day English there are a range of particular constructions, from those where the analysis of (44)a is plausible to those which can only be analysed like (44)b. Between the extremes are constructions which give evidence of both analyses. We can plausibly identify not one but several intermediate types which vary in their degree of closeness to analysis (44)b. If we are prepared to recognise the possibility of intersective gradience between morphosyntactic categories, i.e. word classes, then the consequence seems to be that we must recognise intersective gradience between syntactic constructions. A given string may have for a given speaker an analysis in some sense intermediate between the conventional 'before' and 'after' analyses. The theoretical status of such intermediate structures remains unclear at the moment.

\section{Pronoun case and verb concord}

I have argued (Denison 1996) that there is a person hierarchy in certain case changes. In recent history - the last hundred or so years - there has been a narrowing of the distribution of the subjective case in case-marked pronouns, with objective increasingly the unmarked form. But the loss of subjective case has been uneven. To take a single context as an example:

(49) a. "Not he," said Robert sleepily. (1906 Nesbit, Amulet ix.175) 
b. "Not she," said the Psammead a little less crossly. (ibid. viii.146)

c. "Not they," cried the Princess joyously. (1907 Nesbit, Enchanted castle i.28)

(50) a. "Not me!" was Gerald's unhesitating rejoinder. (ibid. i.26)

b. 'Not us!' said Mabel. (ibid. xi.221)

We find that first person had changed to use of objective case in disjunctive position, (50), by the turn of the twentieth century, while third person was unaffected even in nonstandard usage for several decades longer: cf. (49). Similar changes lasting over longer stretches of the ModE period have begun to remove subjective pronouns from certain other syntactic contexts in most varieties:

(51) a. It is $* \mathrm{I} / \mathrm{me}$.

b. He is taller than $* \mathrm{I} / \mathrm{me}$.

Person no longer appears to be a conditioning factor in any of these contexts, but in the past it was. Whether this is gradience depends on how pronoun case is to be analysed. If (as one referee suggests) pronouns are taken to be collections of features, then we merely have (as another referee suggests) grammatically conditioned variation. But differing case choices in a given variety may reflect a structural difference during the period of variation, as is particularly plausible for the (51)b type: than me analysed as PP, than I certainly not. On that view they can be regarded as exhibiting intersective gradience. I have speculated that the shrinking distribution of the explicitly case-marked subjective pronouns and the increasing numbers of invariant verbs may be interconnected processes (Denison 1996:294-6, 1998:206-12), in effect the gradual loss of subject-verb concord, but that is to stray towards grammaticalisation and so will not be developed here.

Pseudo-imperatives (conditionals)

Compare two different sentence patterns: the imperative and the conditional protasis. I will suggest that there is a gradient between them.

The prototypical imperative has the force of a directive:

(52) Give me some money.

It can occur with please and with tag questions, can co-occur with the subject pronoun when negative, and cannot be used with a VP that is un-self-controllable:

(53) a. Give me some money, please.

b. Give me some money, will you?

c. Don't you give me any money.

d. *Be tall.

Conditional protases may be marked in a number of ways: by a subordinating conjunction, most commonly if; by subject-auxiliary inversion; 
perhaps by the use of a subjunctive verb; in certain circumstances by the imperative. The last-named is of course the relevant option here:

(54) a. "... Stir a whisker, Lungri, and I ram the Red Flower [sc. fire] down thy gullet!" (1894 Kipling, Jungle book, "Mowgli’s brothers" [Macmillan, 1895] 28)

b. Try to be nice and people walk all over you.

This pattern is semantically similar to a conditional (If you stir a whisker ...) and can be called a pseudo-imperative. The verb form is clearly imperative, morphologically the base form of the verb and identical to the present subjunctive, but examples like (54) behave conversely to true imperatives with respect to the properties exemplified in (53).

An intermediate type retains some directive force and all the properties of (53) as well as approximating to a conditional protasis:

(55) Give me some money and I'll let you go.

The conjunction or is similarly used to imply a negative condition, as in:

(56) a. Give me some money or I'll shoot.

b. and do for goodness' sake try and realize that you're a pestilential scourge, or you'll find yourself in a most awful fix. (1898 Grahame, The reluctant dragon 19)

See McCawley (1988:II 708, 737-9), Quirk et al. (1985:931-4). The gradience here runs from true imperatives like (52) to pseudo-imperatives which are mere conditional protases, (54), via an intermediate type, (55)-(56), which has most of the properties of true imperatives combined with the conditional sense. This is certainly semantic gradience. In distributional terms it should count as syntactic gradience too, though whether this is intersective gradience depends on the analysis offered for pseudo-imperatives.

Prepositional verbs

Quirk et al. (1985:1156, 1163-6) and others have argued that two complementary analyses for prepositional verb structures may each capture aspects of the syntax: (57) $[\mathrm{v}$ rely ] [pp on a friend ] and

(58) [v rely on ] [NP a friend ]

They do not, however, appear to argue directly for gradience between the two structures. ${ }^{12}$ Huddleston (1984:200-203) tries to demonstrate that only (57) can be sustained, though if he is right it is clear at least that lexical and semantic structure would be at odds with the syntax for some prepositional verbs. There is in any case great variation among prepositional verbs in the degree of closeness between V and P, as shown by Quirk et al.'s (1985:1166, Fig. 16.15). I will look at one special type. 
Gradience and linguistic change 19

\section{Object to $V$}

There are a number of verbs where the to which was formerly a marker of the following infinitive has now been reanalysed as belonging with the higher verb. Here is the older syntax:

(59) a. ... hatred against anything which might contribute to bring on the disease of which he died. (1858 PEO2.N6 [ARCHER])

b. I have taken to write a little in a penny paper called the Star. (1856 $[O E D])$

c. look forward to be disinherited; had been reduced to learn; I will not submit to be ruined (1867/1867/1838-9 [cited in Denison 1998:266])

Normal usage for (59) since the second half of the nineteenth century would be complementation by to + Ving, with a period of variation for each verb:

(60) a. ... that Celia objected to go (1871-2 Eliot, Middlemarch x.87)

b. but the signs she made of this were such as only Lydgate was used to interpret. (ibid. 1xxviii.777)

(61) a. what he objects to giving, is a little return on rent-days to help a tenant to buy stock (ibid. xxxviii.383)

b. but she had been little used to imagining other people's states of mind (ibid. 1xxviii.777)

Such cases differ from routine alternation between complementation by toinfinitive and complementation by Ving (e.g. prefer to $V \sim$ prefer Ving), since here the to is sufficiently important semantically and syntactically to be retained even with Ving.

I wrote in Denison (1998:266) that the change in complementation reflects two long-term changes. One is the rise of the prepositional verb, as OBJECT and to come to form a unit (and likewise the other cases exemplified in (59)). The other is the drift of the English infinitive from a somewhat more nominal to a verbal character, now virtually complete, and the concomitant dissociation of the infinitive marker to from the homonymous preposition. (In fact it is doubtful whether the English to-infinitive ever was a PP or its verbal formative ever wholly nominal; see now Los 1999:Chapter 11.) Consider the effect of these changes on to depart:

(62) a. Max objected to departure.

b. Max objected to depart.

c. Max objected to departing.

The former parallelism between (62)a and (62)b lost its force, and (62)c became necessary, since the gerund was the only form capable of combining the distribution of an NP with the possibility of its own verbal adjuncts and complements (e.g. departing surreptitiously).

There is another point of view. In (59), (60) and (62)b the to is perhaps simultaneously a preposition and an infinitival particle, since all the verbs 
concerned were used in exactly the same sense either with a to-PP or with a to-infinitive. Compare (62)b with (62)a and (63), respectively, which represent the two straightforward categorial possibilities:

(63) Max refused to depart.

If to in (62)b is partly prepositional, ${ }^{13}$ there is intersective gradience. And the gradience has been resolved by the loss of that construction. This, therefore, can be regarded as another indication of the instability/markedness of intersective gradience.

\section{I'm going Adverbial and $V$}

I conclude this data survey with some examples which will, I predict, be very surprising to all British and some north American speakers:

(64) a. I'm going back there and ask her to marry me. (1906 [OED])

b. "I'm going back and tell Terry and Gottlieb they can go to the devil ..." (1925 S. Lewis, Arrowsmith (Grossett \& Dunlap) xxvii.300)

c. I'm going out and get a girl for my picture. (1933 King Kong [movie], dir. Merian C. Cooper)

d. I'm going in and ask him. (1934 It Happened One Night [movie], dir. Frank Capra)

e. I'm going outside and see what fresh air smells like. (1939 Destry Rides Again [movie], dir. George Marshall)

f. "I'm going over and saddle The Pi [a racehorse] now." (1944 National Velvet [movie], dir. Clarence Brown)

g. I'm going home and see my wife and family. (1947 It's a Wonderful Life [movie], dir. Frank Capra)

$\mathrm{h}$. 'You're going right back into that office and explain to them ... (1949 I Was a Male War Bride [movie], dir. Howard Hawks)

i. I'm going back to business and make myself a little dough. (1955 $[O E D])$

j. I'm going down below and see what I can [unintelligible] (1964 Dr. Strangelove ... [movie], dir. Stanley Kubrick)

k. Sherry and I are going to Florida and get into the seashell business. (1991 G. Keillor, Radio Romance (Faber, 1992) 361)

A similar pattern occurs without and:

(65) a. I'm going back in a coupl'a' years ...open up a dress shop. (1997 L.A. Confidential [movie, set in early 1950s], dir. Curtis Hanson])

b. I'm going up again next weekend. Give it another whirl. (1965 [OED]) Generally speaking, the phenomenon of 'pseudo-coordination' (Quirk et al. 1985:978-9) in standard PDE disallows morphologically different verbs on either side of and: 
(66) a. Try and behave.

b. We will try and behave.

c. *He's trying and behave.

In my data (64)-(65), the second verb is a base form, as is normal in pseudo-coordination, but the first verb is an -ing form, which is not. Notice that the first verb is never directly adjacent to and (or to the second verb in the case of asyndetic coordination), which suggests that the saliency of coordination must be reduced if this construction is to be permitted. It is very tempting to regard the strange construction above as dependent on a grammaticalisation gradient made familiar by Hopper \& Traugott (1993), which runs between the extremes of (67) and (68):

(67) I'm going 1 to the market. [literal verb of motion $+\mathrm{PP}]$

(68) I'm going ${ }_{2}$ to/gonna solve this problem. [auxiliary of future incorporating to]

Since both usages co-exist in PDE, could our construction be a blend involving a reduction operation? Thus, for example,

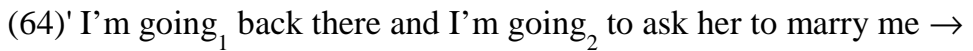

I'm going ${ }_{1+2}$ back there and ask her to marry me

If so, the construction's origin is dependent on the existence of that synchronic gradience. The construction has sporadically been extended further:

(69) I'm coming over there and drag you out myself. (1934 It Happened One Night [movie], dir. Frank Capra)

(70) I'm taking him to the Sheriff and make sure he's destroyed. (1939 Wizard of $O z$ [movie], dir. Victor Fleming)

(71) I'll be turning the key and see if it works. (1997 Margaret McPhee, telephone, attested DD (10 Jan.))

I assume that (69)-(71) are in some way based on the I'm going Adverbial and V construction and do not in themselves involve gradience.

\section{Conclusion}

I have looked at a selection of possible cases of gradience in recent English, including those where the gradience lies in the degree of category membership, i.e. closeness to the prototype - subsective gradience, and the logically similar case where subsective gradience within two adjacent categories can lead to gradience between categories - intersective gradience. Intersective gradience between categories will often involve the soft boundary between syntactic analyses, that is, intersective gradience between constructions. The data I have covered seem to me prima facie awkward for generative models of syntax. I am aware that some 


\section{David Denison}

but not all could be handled under Grammaticalisation, some but not all could be taken as support for Construction Grammar.

Bas Aarts and I are beginning a collaboration in which we will take both horizontal and vertical snapshots of English - synchronic PDE, and recent and current change - using corpora. Possible outcomes of our research project range all the way from finding that gradience is entirely unnecessary or at least insignificant, through deciding that it is a marginal phenomenon which must be grafted on to some standard model of language at appropriate points, to claiming that it is so pervasive as to damage standard models beyond repair. I can't prejudge the outcome. What I have been doing here is more like an investigating magistrate, trying to decide whether there is a case to answer at a full-scale trial. I won't be at all surprised if some of the examples I have given don't stand up to scrutiny, but I think the weight of evidence is sufficient to justify further work. And so I want to suggest that historical linguists should certainly be alive to the possible existence of gradience in their data; and if it is there, they should work to find theoretical approaches which reflect that reality - and convince synchronic linguists of their value. 
Gradience and linguistic change 23

\section{References}

Data sources

ARCHER = A Representative Corpus of Historical English Registers; see footnote 7.

$\mathrm{BNC}=$ British National Corpus; published on the web by Oxford University Computing Services.

FLOB $=$ The Freiburg-LOB Corpus of British English; published on The New ICAME Corpus Collection on CD-ROM.

Frown $=$ The Freiburg-Brown Corpus of American English; published by ICAME.

ICE-GB = International Corpus of English (Great Britain); published by the Survey of English Usage; see footnote 7.

$O E D=$ Simpson, J. A. \& E. S. C. Weiner. 1992. The Oxford English dictionary: CD-ROM version, 2nd edn. Oxford: Oxford University Press.

OED Online = The Oxford English dictionary, $2^{\text {nd }}$ edn. and $3^{\text {rd }}$ edn. in progress; published on the web by Oxford University Press. [searched Sept 2000]

Other individual examples as noted in text.

Secondary works

Aarts, Bas. 1998. "Binominal Noun Phrases in English". Transactions of the Philological Society 96.117-158.

- 2000. Modelling gradience. MS, University College London.

Anderson, John M. 1997. A notional theory of syntactic categories. (= Cambridge Studies in Linguistics, 82.) Cambridge: Cambridge University Press.

anon. 1998. The National Literacy Strategy: framework for teaching, 2nd edn. Sudbury: DfEE Publications.

Bolinger, Dwight. 1976. "Meaning and memory". Forum Linguisticum 1.1-14.

Croft, William. 2000. Explaining language change: an evolutionary approach. (= Longman Linguistics Library.) London: Longman.

Davies, Eirlys. 1986. The English imperative. London: Croom Helm. Denison, David. 1986. “On word order in Old English”. Dutch Quarterly 
Review 16.277-295.

1993. English historical syntax: verbal constructions. (= Longman Linguistics Library.) London and New York: Longman.

1996. "The case of the unmarked pronoun". English historical linguistics 1994: papers from the 8th International Conference on English Historical Linguistics (8.ICEHL, Edinburgh, 19-23 September 1994) ed. by Derek Britton (= Current Issues in Linguistic Theory, 135.), pp. 287-299. Amsterdam and Philadelphia: John Benjamins.

1998. "Syntax". The Cambridge history of the English language ed. by Suzanne Romaine, vol 4, 1776-1997, pp. 92-329. Cambridge: Cambridge University Press.

Emonds, Joseph. 1976. A transformational approach to English syntax. New York: Academic Press.

Gnutzmann, Claus. 1975. Some aspects of grading. English Studies 75.421-33.

Harris, Alice C. \& Lyle Campbell. 1995. Historical syntax in cross-linguistic perspective. (= Cambridge Studies in Linguistics, 74.) Cambridge: Cambridge University Press.

Haspelmath, Martin. 1998. "Does grammaticalization need reanalysis?". Studies in Language 22.315-51.

Henry, Alison. 1997. "Viewing change in progress: the loss of V2 in Hiberno-English imperatives". Parameters of morphosyntactic change ed. by Ans van Kemenade \& Nigel Vincent, pp. 273-296. Cambridge: Cambridge University Press.

Hopper, Paul J. \& Elizabeth Closs Traugott. 1993. Grammaticalization. (= Cambridge Textbooks in Linguistics.) Cambridge: Cambridge University Press.

Huddleston, Rodney. 1984. Introduction to the grammar of English. (= Cambridge Textbooks in Linguistics.) Cambridge, etc: Cambridge University Press.

— \& Geoffrey K. Pullum (in prep.) The Cambridge grammar of English. Cambridge: Cambridge University Press.

Hudson, R. A. 1990. English word grammar. Oxford: Basil Blackwell.

Langacker, Ronald W. 1987. Foundations of cognitive grammar, vol 1. Stanford: Stanford University Press.

Leech, Geoffrey \& Lu Li. 1995. "Indeterminacy between Noun Phrases 
and Adjective Phrases as complements of the English verb". The verb in contemporary English: theory and description ed. by Bas Aarts \& Charles F. Meyer, pp. 183-202. Cambridge, etc.: Cambridge University Press.

Lightfoot, David. 1999. The development of language: acquisition, change, and evolution. (= Blackwell/Maryland Lectures in Language and Cognition, 1.) Malden MA and Oxford: Blackwell.

Los, Bettelou. 1999. Infinitival complementation in Old and Middle English. The Hague: Thesus. [dissertation Ph.D., Vrije Universiteit, Amsterdam, 2000]

Maling, Joan M. 1983. "Transitive adjectives: a case of categorial reanalysis". Linguistic categories: auxiliaries and related puzzles ed. by Frank Heny \& Barry Richards, vol 1 (= Synthese Language Library, 19.), pp. 253-289. Dordrecht: Reidel.

Marchand, Hans. 1969. The categories and types of Present-Day English word-formation: a synchronic-diachronic approach. 2nd edn. Munich: Beck'sche Verlags Buchhandlung.

McCawley, James D. 1988. The syntactic phenomena of English, 2 vols. Chicago: University of Chicago Press.

Newmeyer, Frederick J. 1998. Language form and language function. (= Language, Speech and Communication.) Cambridge MA and London: MIT Press.

Quirk, Randolph et al. 1985. A comprehensive grammar of the English language. London and New York: Longman.

Rosch, Eleanor. 1978. "Principles of categorization". Cognition and categorization ed. by Eleanor Rosch \& B. B. Lloyd, pp. 27-48. Hillsdale NJ: Lawrence Erlbaum.

Ross, John Robert. 1972. "The category squish: Endstation Hauptwort". Papers from the 8th Regional Meeting of the Chicago Linguistic Society 8.316-328.

1973. "A fake NP squish". New ways of analyzing variation in English ed. by Charles-James N. Bailey \& Roger W. Shuy, pp. 96-140. Washington DC: Georgetown University Press.

Sapir, Edward. 1949. Grading: a study in semantics. Selected writings of Edward Sapir: language, culture, and personality, ed. by David G. Mandelbaum, pp. 122-49. Berkeley and Los Angeles: University of California Press / London: 
Cambridge University Press.

Taylor, John R. 1995. Linguistic categorization: prototypes in linguistic theory. 2nd edn. Oxford: Clarendon Press.

Timberlake, Alan. 1977. "Reanalysis and actualization in syntactic change". Mechanisms of syntactic change ed. by Charles N. Li, pp. 141-77. Austin TX and London: University of Texas Press.

Warner, A. R. 1990. "Reworking the history of English auxiliaries". Papers from the 5th International Conference on English Historical Linguistics: Cambridge, 6-9 April 1987 ed. by Sylvia Adamson et al. (= Current Issues in Linguistic Theory, 65.), pp. 537-558. Amsterdam and Philadelphia: John Benjamins. 
Gradience and linguistic change 27

\section{Notes}

${ }^{1}$ I had a period of Research Leave in 1996-97 for my work on a pronoun hierarchy in syntactic change (mentioned below). During that time I had the opportunity to read and reflect on several of the ideas discussed here, and I am grateful to the British Academy for their contribution to that period of leave. Revision of this paper has been greatly aided by helpful comments received from Bas Aarts, Dick Hudson, Alison Cort and two anonymous referees, though of course the usual disclaimers apply.

2 This revolution in primary school teaching of English language was launched in 1997-98. After protests by a few linguists who saw the original glossary which had been issued to schools (one of the appendices in Section 3 of anon. 1998), a revised and extended glossary was commissioned in collaboration between them and the Department for Education and Employment and published on the web in 2000 at http://www.standards.dfee.gov.uk/literacy/glossary/

${ }^{3}$ Aarts (2000) notes a few recent attempts to consider fuzzy categories within formal syntax.

${ }^{4}$ For the quantifiers much and few Hudson finds evidence for categorisation as both Adjective and Noun (1990:307-8), which threatens to pull this case into the arena of intersective gradience. Aarts (2000) makes the following point: "It is important to see that the existence and extent of pervasiveness of I[ntersective] $\mathrm{G}$ [radience] are a function of the categories of the adopted taxonomic framework. Thus, for example, if it is claimed that there is boundary fluidity between two categories $\alpha$ and $\beta$, then it must first be established that $\alpha$ and $\beta$ actually exist as form classes, i.e. that they are 'grammatically real'."

5 I note that in a paper first published in 1944, Sapir says without comment: "More and less apply to both count and measure." (1949:131).

${ }^{6}$ An anonymous reviewer points out that powerhouse is less easy to imagine as a predicative adjective than as an attributive one. If true - and certainly I have no examples of predicative adjectival powerhouse - example (10) would still be sufficient to classify the word as an adjective.

${ }^{7}$ I am grateful to Bas Aarts for access to examples from the International Corpus of English (Great Britain) (ICE-GB) and British National Corpus (BNC), and to Douglas Biber and Edward Finegan for the use of A Representative Corpus of Historical English Registers (ARCHER). For other data sources see the list of references.

${ }^{8}$ Scholars disagree on whether semantic gradability can be found in nouns. Gnutzmann, for example, argues as follows (1975:421): “Though gradability 
belongs to the province of semantics, it is nevertheless not completely detached from grammar: in opposition to Sapir [1949] we would like to claim that only adjectives and adverbs admit gradation.".

9 A referee rightly points out that definitions of the category Adjective in earlier English could not include an inability to take NP complements, so that examples like (41) would not in themselves demonstrate prepositional character at the time of their writing. In that case, though, what they might demonstrate is that the whole categories $\mathrm{A}$ and $\mathrm{P}$ have since become better differentiated: most complement-taking adjectives have either lost that property or now take PP rather than NP complements.

${ }^{10}$ Newmeyer (1998:201-2) would claim that it can be either $\mathrm{P}$ or A but not both simultaneously.

${ }^{11}$ For an introduction to Eleanor Rosch's psychological work on categories, see for instance Rosch (1978), Taylor (1995).

12 Elsewhere in the verb complementation system they argue for intersective gradience between certain infinitival structures (1985:1216-20).

${ }_{13}$ Syntactic proof is difficult to find. Stranding of prepositions (That's what she objected to) is not the same as ellipsis after infinitival to (And she refused to), which in any case is only found sporadically from the late eighteenth century and is rare before mid-nineteenth century (Denison 1998:201-2). Coordination of an infinitive with a nominal after to is very rare; a fifteenth-century example in Denison (1993:189) repeats to before NP and before verb. For Old English see Los (1999:242). 